\title{
Microcontroller PIC 16F877A Standard based on Solar Cooker using PV- Evacuated Tubes with an Extension of Heat Integrated Energy System
}

Arulraj Simon Prabu ( $\sim$ s.shanmugam1982@gmail.com )

Sriram Engineering College https://orcid.org/0000-0002-7974-5675

Venkatesan Chithambaram

PERI IT: PERI Institute of Technology

Maria Anto Bennet

Veltech: Vel Tech Rangarajan Dr Sagunthala R\&D Institute of Science and Technology

Sengottaiyan Shanmugan

Koneru Lakshmaiah Education Foundation

\section{Catalin Iulian Pruncu}

Imperial College London - Wye Campus: Imperial College London

\section{Luciano Lamberti}

POLIBA: Politecnico di Bari

Ammar Hamed Elsheikh

Tanta University

Hitesh Panchal

Government Engineering College Raipur: National Institute of Technology Raipur

Balasubramani Janarthanan

Karpagam Academy of Higher Education: Karpagam University

\section{Research Article}

Keywords: Solar cooker, charge controller, evacuated tubes, PV panel

Posted Date: July 6th, 2021

DOl: https://doi.org/10.21203/rs.3.rs-596799/v1

License: (a) (i) This work is licensed under a Creative Commons Attribution 4.0 International License. Read Full License 
16863-2. 
Microcontroller PIC 16F877A standard based on Solar Cooker using PV- Evacuated tubes with an extension of heat integrated energy system

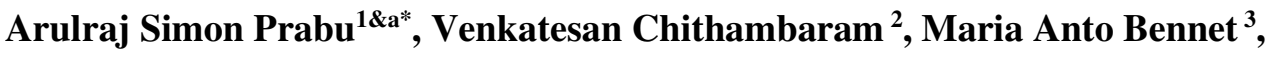
Sengottaiyan Shanmugan ${ }^{4 *}$ Catalin Iulian Pruncu ${ }^{5 \& b}$, Luciano Lamberti ${ }^{6}$ Ammar Hamed Elsheikh ${ }^{7}$, Hitesh Panchal ${ }^{8}$ Balasubramani Janarthanan'

${ }^{1}$ Department of Electronics and Communication Engineering, Sriram Engineering College, Perumalpattu, Chennai, Tamil Nadu, India - 602024 .

\begin{abstract}
${ }^{a}$ Department of Physics, Dhanalakshmi College of Engineering, Tambaram, Chennai, Tamil Nadu, India-601301.
\end{abstract}
${ }^{2}$ PERI Institute of Technology, No.1, Near, West Street, Tambaram, Mannivakkam, Tamil Nadu 600048, India.

${ }^{3}$ Department of Electronics and Communication Engineering, Vel Tech Rangarajan Dr. Sakunthala R\&D Institute of Science and Technology, Avadi, Chennai, Tamil Nadu, India - 600062.

\footnotetext{
${ }^{4}$ Research Centre for Solar Energy, Department of Physics, Koneru Lakshmaiah Education Foundation, Green
}

Fields, Guntur District, Vaddeswaram, Andhra Pradesh 522502, India.

${ }^{5}$ Design, Manufacturing \& Engineering Management, University of Strathclyde, Glasgow, G1 1XJ, UK.

${ }^{\mathbf{b}}$ Department of Mechanical Engineering, Imperial College London, Exhibition Rd., London, UK

${ }^{6}$ Dipartimento di Meccanica, Matematica e Management, Politecnico di Bari, Bari, Italy

${ }^{7}$ Department of Production Engineering and Mechanical Design, Tanta University, Tanta 31527, Egypt.

${ }^{8}$ Mechanical Engineering Department, Government Engineering College Patan, Gujarat, India- 384265.

${ }^{9}$ Department of Physics, Karpagam Academy of Higher Education, Eachanari, Coimbatore, Tamil Nadu, India 641021.

Emails ID : ${ }^{1}$ simonprabu07@gmail.com, ${ }^{3}$ chithambaramv@gmail.com, ${ }^{3}$ bennetmab@gmail.com,

${ }^{4}$ s.shanmugam1982@gmail.com, ${ }^{5}$ Catalin.pruncu@ starth.ac.uk, ${ }^{6}$ luciano.lamberti@poliba.it

7 ammar_elsheikh@f-eng.tanta.edu.eg, ${ }^{8}$ engineerhitesh2000@gmail.com, ${ }^{9}$ bjanarthanan2010@ gmail.com

* Corresponding author, E-mail address: ${ }^{1}$ simonprabu07@gmail.com and s.shanmugam1982@gmail.com.

\title{
Abstract
}

The unavailability of sunlight during nighttime and cloudy weather condition has limited the usage of solar cookers throughout the day. This study will attempt to engineer a solar cooker with PV (Photovoltaic panel), evacuated tubes with CPC reflectors, battery and charge controller using the microcontroller PIC 16F877A. A mathematical model is developed to predict the electrical power $\left(\mathrm{E}_{\mathrm{p}}\right)$ required during cloudy weather condition and nighttime as well as the temperatures occurring at different parts of the cooker. The proposed model is validated against experimental observations gathered for one of the typical working days of the system. The cooker is tested for various cooking 
loads to find the cooking time and it is proven that the proposed cooker can be utilized over 24/7

36 without interruption.

Keywords: Solar cooker, charge controller, evacuated tubes, PV panel

\section{Introduction}

41 Solar cookers have immense intensity to make food for smaller and larger communities, which

42 include hospitals, colleges, industries etc. Commercial Box-type solar cookers are limited to use 43 due to their non-functionality during cloudy weather and nighttime. These limitations have been

44 slowly overcome making efforts to introduce electrical backup by solar panel with heating coils to 45 supply auxiliary heat during daytime and storage of electrical power in the battery whose charge can be extracted to supply for the heating coil during nighttime and cloudy weather for cooking. Researchers carried out experimental work with their proposed cookers with electrical backup and heating coil to supply heat energy for cooking. Results of the study have been documented for the welfare of the researchers in the respective field. The solar cooker technology is clean, efficient with a wide range of possible applications in eliminating pollution Thamizharasu et al., (2020). Since the amount of solar box cookers is fixed, many scientists are trying to develop efficient solar cooking systems Shanmugan et al., (2020). The exploitation of technological developments Palanikumar et al., (2021), including numerical simulation Bhavani et al., (2019), is an important approach that precedes experimental work to reduce the waste of time, effort by Bhavani et al., (2021) and money Palanikumar et al., (2019). Since solar cooking gathered a lot of attention, a brief survey of previous studies on this subject is now presented Bhavani et al., (2018). Palanikumar et al., (2021) studied a stepped solar cooker using a bar plate with $\mathrm{SiO}_{2} / \mathrm{TiO}_{2}$ nanoparticles at different concentrations equal to 10 and $15 \%$. The experimental results confirmed that solar cooker efficiency reaches $37.69 \%$ for a $10 \%$ concentration of $\mathrm{SiO}_{2} / \mathrm{TiO}_{2}$ nanoparticles and $49.21 \%$ for a $15 \%$ concentration. Rakesh Kumar et al. (2001) have designed a community type solar cooker using 5 evacuated tube solar collectors. Thermal analysis has been done and simulation results confirmed the possibility of cooking of several batches. A prototype solar cooker

63 incorporated with phase change material unit has been fabricated by Sharma et al. (2005) to utilize

64 in late evening and nighttime. It has been inferred that due to PCM material erythritol, cooker can 65 be used in the evening. 
Pinar Mert Cuce (2018) compared box-type solar cookers with and without Bayburt stone as

67 sensible heat storage material, which has low density and high specific heat. It is observed that adopting the Bayburt stone in the cooker enhanced the thermal performance of solar cooker compared to cooker without the stone. Saxena and Agarwal (2018) designed a hybrid solar cooker with 200W halogen lamp and trapezoidal air duct and 450 hollow copper balls. Results confirmed the efficient performance of the proposed cooker with forced convection in all climatic conditions.

Mohammad Hosseinzadeh et al. (2020) fabricated portable evacuated tube solar cooker and analytically studied it using Taguchi analysis. It was found that the maximum operative parameters are solar radiation, absolute pressure of vacuum tubes. Arunchala and Kundapur (2020) presented a thorough review of solar cookers with and without reflectors, panels, funnels etc. highlighting the findings of the various studies. Omara et al. (2020) reviewed usage of different phase change materials in solar cookers: they highlighted the results obtained by the researchers and mentioned the optimal quantity of PCM to be used. Masum Ahamed et al. (2020) studied the performance on a solar cooker using parabolic reflectors. Results demonstrated the maximum reflection of solar radiation by mylar tape reflector.

Devan et al. (2020) reviewed solar cookers with tracking mechanism. The review emphasized the tracking system using microcontrollers, manual tracking and thermal and parabolic systems. Mawire et al. (2020) used two cooking pots with sunflower oil sensible heat storage fluid and erythritol phase change material for cooking during on/off sunlight, which is an experimental that sunflower grease cooking vessel has better performance with lesser heat utilization efficiency.

86 Coccia et al. (2020) tested a solar cooker provided with dual penned container filled by phase change material of $2.5 \mathrm{~kg}$ of erythritol. Experimental results proved the extension of load cooling time by $351.16 \%$. Thirugnanam et al. (2020) obtainable comprehensive evaluation on phase change materials used a solar cooker and mentioned the quality requirements of PCM is used the designs. Bhave and Kale (2020) used a phase change material solar salt and proved the possibility of frying and cooking in the shade inside the kitchen. Nokhosteen and Sobhansarbandi (2020)

92 adopted the Resistance Network (RN) model to predict the performance on solar collectors using 93 heat pipe evacuated tube. Results of a model was in excellent agreement with the experimental 94 work with a minimum error of $10 \%$.

95 Very recently, Hosseinzadeh et al. (2021a) designed and tested a solar cooking unit incorporated with solar collector and used thermal oil based nanofluids. It is observed that SiC-oil 
nanofluid dominates other nanofluids $\left(\mathrm{TiO}_{2}\right.$-oil and $\mathrm{SiO}_{2}$-oil $)$ on the overall energy efficiency of

98 the system. Hossienzadeh et al. (2021b) have studied a solar cooker as using multi-walled carbon

99 nanotube oil nanofluid in an indirect solar cooker with collector and cooking unit. The study

100 revealed the enhancement of the model.

101 Current work, as a solar cooker with PV, evacuated tubes, charge controller PIC 16F877A,

102 Nichrome heating coil and battery have been analyzed and studied an analytical model. The goal

103 is to predict the concert with a design. Mathematical expression derived an electrical power $\left(\mathrm{E}_{\mathrm{p}}\right)$

104 based on the heat transfer process mechanisms are designed an evacuated tube collector, Nichrome

105 coil wounded cooking vessels, charge controller, solar panel and a battery. The cooker is integrated

106 with thermal and photovoltaic power to make it possible cooking over 24/7 without interruption.

107 The article is structured in place of tracks on solar cooker and designated the next segment.

108 Third section as a paper presents the thermal simulation model established new design

109 performance. Last two sections current the consequences of the simulation model showing their

110 agreement with experimental measurements. The main findings of the study are summarized in

111 the concluding section.

112

\section{Design of the cooker}

114 The compatible solar cooker developed in this study has four components:

$115>$ Evacuated tubes with high vacuum $\left(\mathrm{P}<5 \times 10^{-3} \mathrm{mbar}\right)$ enclosed in rectangular wooden box

116 with parabolic trough reflectors;

$117>$ Solar photovoltaic panel $(2 \times 100 \mathrm{~W})$;

$118>12$ V 75AH Battery;

$119>$ Stove with two vessels for cooking.

120 A compatible solar cooker with photovoltaic panel and evacuated tubes (Solar Chulha) has

121 been designed and fabricated. Evacuated tubes with high vacuum $\left(\mathrm{P}<5 \times 10^{-3} \mathrm{~Pa}\right)$ have been used

122 in the proposed cooker and the system is used for producing hot water at about $75^{\circ} \mathrm{C}$ for cooking.

123 Parabolic trough reflectors are designed and the evacuated tubes have been fixed on the focal line

124 of the trough near obtain determined a solar energy. A copper tubes carrying heat transfer fluid

125 (water) is made to run through an evacuated tubes near excerpt temperature received by a tubes

126 performance is higher. Photovoltaic panel of power output $200 \mathrm{~W}$ has been used to charge $12 \mathrm{~V} 75$

127 AH battery. The charge from the battery is used to heat the heating filament (Nichrome) covering 
128 the cooking vessel. Hot water from the evacuated tubes is further heated up to the boiling point

129 and food is cooked easily. Furthermore, DC electrical power from the panel is stored in the battery

130 during daytime and can be used during night. Figures 1 through 3 show the photograph of the

131 solar cooker and its different components.

\section{Thermal Model of the Solar Cooker}

133 Five evacuated tubes are mounted on the focal line of the CPC reflector and are enclosed in a

134 rectangular box made of plywood. Glass wool insulators are introduced in the gap between the

$135 \mathrm{CPC}$ reflectors and glass cover of thickness $3 \mathrm{~mm}$ has been used to cover the rectangular box. The

136 evacuated tubes have length of about $490 \mathrm{~mm}$ while the inner and outer diameters of each tube are

$13733 \mathrm{~mm}$ and $44 \mathrm{~mm}$, respectively. Copper tube of diameter $3 \mathrm{~mm}$ are made to run through the

138 evacuated tubes continuously from the first evacuated tube to last evacuated tubes, which are

139 arranged in a sequence inside the rectangular box. Cooking liquid allowed near movement

140 complete a copper pipes through an inlet first evacuated tube using a valve to control the movement

141 amount on cooking liquid.

142 Collector performance determined through finding the total energy absorbed and utilized

143 by the collector and the first law of thermodynamics is used an energy balance equation as

$$
\sum E_{a b}=E_{u t}
$$

146 where $E_{a b}$ is the energy absorbed or transferred to the collector and $E_{u t}$ is the energy an increase

147 the temperature levels (fluid acts), useful energy utilized by the collector is:

$$
Q_{u}=m C_{p w}\left(T_{\text {out }}-T_{\text {in }}\right)
$$

151 where

$152 m-$ Mass flow rate of working fluid water $(\mathrm{kg})$

$153 C_{p w}-$ Specific heat capacity of water $\left(\frac{\mathrm{J}}{\mathrm{kgK}}\right)$

$154 T_{\text {out }}$ - Output temperature of water $(K)$

$155 T_{\text {in }}-$ Inlet water temperature $(K)$

157 The energy effectively collected by the system is:

$$
Q_{\text {col }}=A_{\text {col }} F_{R} \cdot\left[I_{t} \cdot(\tau \alpha)_{e}-U_{L}\left(T_{\text {aref }}-T_{a}\right)\right]
$$


where:

$160 Q_{c o l}-$ Total energy collected by the collector;

$161 A_{\text {col }}-$ Area of the collector $\left(m^{2}\right)$;

$162 F_{R}-$ Collector efficiency factor;

$163 I_{t}-$ Solar radiation $\left(\mathrm{W} / \mathrm{m}^{2}\right)$;

$164(\tau \alpha)_{e}-$ Effective transmittance absorptance product;

$165 U_{L}-$ Total heat loss efficiency $(\mathrm{W} / \mathrm{mK})$;

$166 T_{\text {aref }}-$ Average temperature of the refrigerant $(K)$;

$167 T_{a}-$ Ambient Temperature $(K)$.

From the energy collected, it is possible to calculate the efficiency of the solar device as:

$$
\eta_{e}=\frac{Q_{c o l}}{A_{c o l} I_{t}}
$$

171

172 Hence, efficiency can be expressed as:

173

174

$$
\eta_{e}=F_{R} \cdot(\tau \alpha)_{e}-\frac{F_{R} U_{L}\left(T_{\text {aref }}-T_{a}\right)}{I_{t}}
$$

175 Fig. 4 shows a schematic representation of the displaced pipe with a copper pipe running it. Copper tube is shaped as a u-tube and inserted in the displaced pipe. Copper tube an outlet from the first displaced pipe is an inlet to a second displaced pipe and so on. Solar energy entered complete a transfer materials are absorbed onto the evacuated tubes. Heat energy is connected to the copper tube inside the fluid water is moved to the working process. A cooking fluid (i.e. working fluid water flowing out through the outlet of the fifth evacuated tube) reaches a maximum temperature. The flow rate of water through the copper tube is maintained in such a way to absorb enough

182 thermal energy from the copper throughout its passage through the tube till it reaches the outlet.

183 The design an outer glass cover is used an energy balance equation (i.e. the covering glass for the 184 evacuated tube collector) as follows.

Covering glass cover

$$
I_{t} A_{g} \propto_{g}+h_{\text {cogg }}\left(T_{\text {eog }}-T_{o g}\right) A_{g}+h_{\text {rogg }}\left(T_{\text {eog }}-T_{o g}\right) A_{g}=h_{\text {coga }}\left(T_{o g}-T_{a}\right) A_{g}+h_{\text {roga }}\left(T_{o g}-\right.
$$

$$
\left.T_{a}\right) A_{g}
$$


Outer glass tube of the evacuated tube

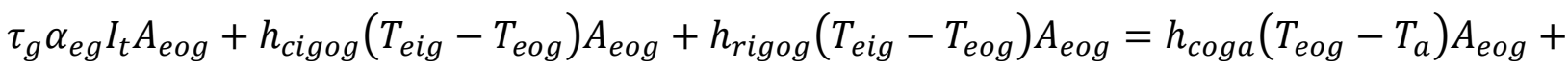

Inner glass tube of the evacuated tube

Copper tube

$$
h_{\text {cigct }}\left(T_{\text {eig }}-T_{c}\right) A_{c}+h_{\text {cigct }}\left(T_{\text {eig }}-T_{c}\right) A_{c}=h_{c c t w}\left(T_{c t}-T_{w}\right)+h_{r c t w}\left(T_{c t}-T_{w}\right)
$$

\section{Water} 213 electrical backup.

$$
m_{w} C_{w} \frac{d T_{w}}{d t}+h_{c c t w}\left(T_{c t}-T_{w}\right)+h_{r c t w}\left(T_{c t}-T_{w}\right)=0
$$

Eqs. (6) through (9) have been solved for the temperature of the outer glass cover $\left(T_{o g}\right)$, for $T_{e o g}$ is outer glass tube of the evacuated tube, as $T_{e i g}$ is inner glass tube of the evacuated tube, $T_{c}$ is copper tube. The evacuated tube water is used in a solar collector that solution of the Eq. (10) is obtained and it gives the outlet temperature $\left(\mathrm{T}_{\text {out }}\right)$.

Outlet cooking fluid temperature from the evacuated tube collectors reaches a maximum of $80^{\circ} \mathrm{C}$ and is hence introduced into the cooking vessel, which is fitted in a wooden enclosure. The sides and bottom of the cooking vessels are well insulated using glass wool insulator with thermal conductivity of $0.0038 \mathrm{~W} / \mathrm{mK}$. The cooking vessel is made of aluminum and provided with an aluminum lid. Nichrome coil is wounded on the sides of the cooking vessel to provide the

The hot cooking fluid output the displaced pipe accumulator is introduced in the cooking vessel to cook food. Hot water temperature is $T_{\text {out }}$ from an evacuated pipe collector and used for cooking fluid the energy again equations base of a cooking vessel can be written as:

$$
P_{e} A_{b} \times t+T_{\text {out }} A_{b} S M=h_{b s} A_{b}\left(T_{b}-T_{a}\right)
$$


Similarly, the energy balance for the sides of the cooking vessel is stated as:

$$
P_{e} A_{s} \times t+T_{\text {out }} A_{s} S M=h_{b s} A_{s}\left(T_{s}-T_{a}\right)
$$

222 The outlet water from the evacuated tube into the cooking vessel absorbs the thermal energy 223 supplied by the Nichrome heating coil surrounding the base and sides of the cooking vessel. The cooking fluid temperature increases due to the absorption of energy from electrical back up and thus food items in the vessel can be cooked. Therefore, the temperature of cooking fluid $\left(T_{c f}\right)$ can be balanced with respect to that of the absorbed energy using the relationship:

$$
\frac{d T_{c f}}{d t}+a T_{c f}=f(t)
$$

where $a$ and $f(t)$ are constants that can be determined from the equations relative to temperature components of the evacuated tube collector, Nichrome heating coil and cooking vessel respectively.

At $t=0, T_{c r}=T_{c f o}$ and due to the initial condition from Eq. (13). We are writing as

$$
T_{c f}=\frac{f(t)}{a}\left(1-e^{-\propto t}\right)+T_{c f 0} e^{-\propto t}
$$

where $\alpha$ is a constant of a cooker with a different heat transfer coefficients by a system

As an electrical power is supplied due to the conversion of absorbed solar energy by the panel of power $200 \mathrm{~W}$, it is indispensable to consider the incoming solar energy by the aperture of the panel in the respective interval of time. It is also considered that the charge controller is capable of charging the battery and supplying electrical power to the Nichrome heating coil without any interruption. Therefore, the input energy for the cooker with electrical back up can be written as:

$$
E_{i}=I_{t} A_{p}
$$

242 The energy output of the cooker is given by:

$$
E_{o}=\frac{m C_{f}\left(T_{c f}-T_{o u t}\right)}{t}
$$

244 From the two equations (15) and (16), the thermal energy efficiency by a system is

$$
\eta=\frac{E_{o}}{E_{i}}
$$

246 Therefore,

$$
\eta=\frac{m C_{f}\left(T_{c f}-T_{o u t}\right)}{I_{t} A_{p} t}
$$




\section{Results and Discussion}

The evacuated tube collector was tested separately with a temperature component, which

250 is measured along sun rays, ambient temperature intermittently using solar radiation monitor. The 251 measured data (solar radiation and ambient temperature) relative to one of the typical experimental 252 days was used for calculations as shown in Fig. 5. The variation with a glass cover temperature an 253 evacuated tube solar collector has been respected to the time allows one liter water, which is 254 allowed to flow over the copper tube as shown in Fig. 6. The glass cover temperature influences 255 the temperature of $62^{\circ} \mathrm{C}$ in 50 minutes as the glass cover covering the enclosure of the evacuated 256 tube collector has larger aperture to receive the sun energy.

257 Energy balance equation of a soluction from Eq. (6) is obtained a glass cover temperature for the 258 theoretical value also determined. It is showed from Fig. 6 that theoretical and experimental values 259 have practically the same trend throughout time. Therefore, the analytical solution for the glass 260 cover can be used for the simulation model in any other similar location having same climatic 261 conditions.

262 Fig. 7 compares the theoretical and experimental values for the temperature of an outer 263 glass tube with an evacuated tube collector. Numerical results created an analytical solution an 264 outer glass tube energy balance equation (Eq. (7)) clearly show that the computed values follow 265 experimental values all the time without much deviation. An outer glass with an evacuated tube 266 is received a thermal energy from trapped and the remaining amount of energy is sent to the path 267 of the temperature component of the system.

268 An inner glass tube with an evacuated tube in various temperatures were calculated by 269 solving Eq. (8) and the numerical values were plotted along with the experimental observations in 270 Fig. 8. Heat energy reaching an internal glass pipe is trapped due to evacuation, which is an inner 271 glass tube temperature as gradually increases with beginning and abruptly increased due to 272 evacuation. It appears from the figure that theoretical predictions and experimental observations 273 agree very well throughout the working time due to the exact evaluation of the component created 274 an energy balance equation.

275 A copper tube (evacuated tube) has been inserted into the U-shaped pipe an output is first 276 provided the input of the second and so on. The copper tube receives the heat energy from an inner 277 glass tube, which is trapped inside the tube energy without much loss. 
278 A copper tube is showed in Fig. 9 with a variation's temperature by deference near period; 279 analytical results created solution an energy balance equation was obtained from Eq. (9). The 280 thermal energy absorbs by the copper tube with flowing water throughout, its path. It reaches the 281 outlet of the displaced pipe collector temperature by a fluid becomes maximum.

282 The water temperature increases in every step (i.e. every evacuated tube) and water outlet from the 283 last evacuated tube reaches the maximum temperature. It was solved energy equations 284 determining a water temperature with an outlet to a collector, when the results were evaluated. Fig. 28510 is valued an experimental data and analytical results are plotted with respect to time. An outlet 286 of evacuated tube collector with temperature is reached the maximum of $96^{\circ} \mathrm{C}$.

287 Furthermore, the theoretical outcomes have been closed the contract an investigational 288 explanations. It is possible to get low pressurized steam if the flow rate of water through the copper 289 pipes were adjusted an intermittent steam may be produced with optimum movement amount of 290 an aquatic.

291 Discussed above results an indicate simulation model developed in this study predicted the 292 temperature components of the system with very small errors. Therefore, for the evacuated tube 293 collector, the model can be used to simulate the collector for any location and it may be possible 294 to optimize design parameters for community-based installments.

295 The outlet water was introduced into the cooking vessel seeing that the water itself has to 296 move through a certain distance in open environment and flow into the cooking vessel. Hence, 297 an evacuated tube collector water temperature through an outlet is decreases by some extent before 298 it reaches the cooking vessel. During its path, some energy was lost to the surroundings and water 299 temperature an inlet of a cooking vessel decreased to $74^{\circ} \mathrm{C}$. Therefore, after the introduction of hot 300 water into the cooking vessel, auxiliary heat energy is supplied by electrical backup.

$301 \quad$ The base and sides of the cooking vessel receive heat energy from electrical backup as well 302 as via convection of heat energy from the cooking fluid to the base and sides. Therefore, it is 303 indispensable to find the analytical results for the temperature of the base and side of the vessel 304 based on energy process. An analytical solution for the two components was obtained and it is 305 plotted along with experimental observations as shown in Fig. 11 and Fig. 12 a directive that 306 confirm to the model. It is variations temperature in base, for side cooking vessel with respect to 307 the working hours. The theoretical results were moral contract by an experimental observations. 
Therefore, thermal simulation model developed in energy process of a temperature component gives precise results and can be used for portraying the system behavior.

An evacuated tube collector is allowed flow hot water into cooking vessel, thus supplying the cookery liquid. A cooking fluid temperature at the cooking vessel is nearly $74^{\circ} \mathrm{C}$ and auxiliary

312 heat is supplied to the cooking fluid by the Nichrome coil wounded over the sides in cooking pot.

313 A fluid of a cooking temperature raises, food is cooked. An analytical solution for the cooking

314 fluid temperature is used to calculate a cooking fluid temperature any instant of period with Eq.

315 (14). An experimental observations and the theoretical calculations done for cooking fluid

316 temperature are associated with a Fig. 13. It can be seen that theoretical and experimental results

317 are as expected and agree very well with small deviations. This is due to the intermittent nature of 318 cooking fluid temperature an incorporated to a food item.

319 The thermal model developed for determining temperature elements of the cooker is moral arrangement by an investigational consequence. Cooking fluid temperature is used to find the energy output of the proposed system with electrical backup. Energy output with electrical backup was calculated then which is experimental follow of water fever from an evacuated pipe collector was $75^{\circ} \mathrm{C}$ and it is fed into the cooking vessel. The temperature was further increased to $96^{\circ} \mathrm{C}$ by utilizing the electrical backup for a time period of 15 minutes. The temperature of the cooking fluid should be sustained for 45 minutes to cook $1 \mathrm{~kg}$ of rice. The electrical backup required to sustain the temperature of the cooking fluid was found to be 0.15 unit of electricity with power of $160 \mathrm{~W}$. Energy input to the cooker can be calculated using Eq. (15) and the efficiency of the cooker is estimated with the energy output and energy input using Eq. (18).

The resulting efficiency of the proposed system with a load of $1 \mathrm{~kg}$ of food stuff was found to be $36.52 \%$. This was achieved by using the electrical backup supplied by the Nichrome heating

\section{Conclusion}

334 The paper described a novel solar cooker design including photovoltaic panels, evacuated tubes with CPC reflectors, battery and charge controller using the microcontroller PIC 16F877A. An analytical model was established with a simulating the thermal performance on the cooker, it is validated against experimental measurements.

338 The subsequent inferences have been strained from this study: 
339 (i) Figure of Merit $\left(\mathrm{F}_{1}\right)$ and Figure of Merit $\left(\mathrm{F}_{2}\right)$ for the cooker have been found as 0.1197 and 0.4018, which met the value of Bureau of Indian Standard.

341 (ii) As the cooking vessel is well thermally insulated using glass wool of thermal conductivity $0.0038 \mathrm{~W} / \mathrm{mK}$, the temperature attained using the electrical backup can be maintained for a

344 (iii) The water output temperature an evacuated tube is reached a maximum of 75 to $80^{\circ} \mathrm{C}$ within a short interval of time with optimum movement amount to the inlet an evacuated pipe.

(iv) Validation of the thermal simulation model demonstrated the usability of the model for optimizing design parameters. Furthermore, the model can be utilized for large scale installations.

(v) The thermal efficiency of the cooker is $36.52 \%$ and the cooker can be used over the 24 hrs cycle as it is provided with a battery to store the charge.

(vi) The cooker can be used for cooking as well as frying food stuff as it is provided with electrical back up of $160 \mathrm{~W}$.

353 (vii) The cooker is affordable to a common man as the cost of the cooker is INR 10,500/- only.

\section{Nomenclature}

$356 \quad I_{t} \quad-\quad$ Intensity of solar radiation $\left(\mathrm{W} / \mathrm{m}^{2}\right)$

$357 \tau_{g} \quad-\quad$ Glass cover transmittance

$358 \quad \alpha_{e g} \quad-\quad$ Absorptivity of the evacuated glass tube

$359 A_{\text {eog }} \quad$ - Outer and evacuated glass tube areas $\left(\mathrm{m}^{2}\right)$

$360 \quad A_{g} \quad-\quad$ Total glass cover areas $\left(\mathrm{m}^{2}\right)$

$361 \quad \alpha_{g} \quad-\quad$ Glass cover absorptivity

$362 A_{c} \quad-\quad$ Copper tube areas $\left(\mathrm{m}^{2}\right)$

$363 h_{\text {cogig }}-\quad$ Convective heat transfer coefficient from outer - inner glass tube from an evacuated $364 \quad$ tube $(\mathrm{W} / \mathrm{mK})$

$365 h_{\text {rogig }}-\quad$ Radiative heat transfer coefficient from outer - inner glass tube from an evacuated 366 tube $(\mathrm{W} / \mathrm{mK})$

$367 \quad T_{\text {eog }} \quad-\quad$ Outer glass tube an evacuated tube temperature (K)

$368 T_{\text {eig }} \quad-\quad$ Inner glass tube an evacuated tube temperature (K)

$369 \quad A_{\text {eig }} \quad$ - Inner glass tube an evacuated tube area $\left(\mathrm{m}^{2}\right)$ 
$370 h_{\text {cigct }}-\quad$ Convective heat transfer coefficient from inner glass - evacuated to copper tube $(\mathrm{W} / \mathrm{mK})$

$372 h_{\text {rigct }}$ - Radiative heat transfer coefficient from inner glass - evacuated to copper tube $(\mathrm{W} / \mathrm{mK})$

$374 h_{\operatorname{cog} g}-$

375

$376 h_{\text {rogg }}-$

377

$378 h_{\operatorname{cog} a}-$

$379 h_{\text {roga }}$ -

$380 h_{\text {cigog }}-$

$382 h_{\text {rigog }}-$

383

$384 h_{c c t w}-$

$385 h_{r c t w}{ }^{-}$

$386 T_{w} \quad-$

$387 T_{c t} \quad-$

$388 \quad E_{i} \quad$

$389 A_{p} \quad$ -

$390 \quad P_{e} \quad$

$391 A_{b} \quad-$

$392 A_{s}$ -

$393 t \quad$

$394 T_{\text {out }}$

$395 \quad S$ -

$396 M$

$397 h_{b s}$

$398 T_{b}$

$399 T_{a}$

$400 \quad T_{s}$
Convective heat transfer coefficient from outer glass cover to outer glass tube of the evacuated tube $(\mathrm{W} / \mathrm{mK})$

Radiative heat transfer coefficient from outer glass cover to outer glass tube of the evacuated tube $(\mathrm{W} / \mathrm{mK})$

Convective heat transfer coefficient from outer glass cover to the ambient (W/mK) Radiative heat transfer coefficient from outer glass cover to the ambient (W/mK) Convective heat transfer coefficient from inner to outer glass tube of the evacuated glass tube

Radiative heat transfer coefficient from inner to outer glass tube of the evacuated glass tube

Convective heat transfer coefficient from copper tube to water $(\mathrm{W} / \mathrm{mK})$

Radiative heat transfer coefficient from copper tube to water (W/mK)

Water inside the copper tube temperature $(\mathrm{K})$

Copper tube temperature $(\mathrm{K})$

Energy input cooker $\left(\mathrm{J} / \mathrm{m}^{2}\right)$

Aperture area solar panel $\left(\mathrm{m}^{2}\right)$

Electrical power supplied through Nichrome coil to the base (W)

Cooking vessel base areas $\left(\mathrm{m}^{2}\right)$

Cooking vessel side wall areas $\left(\mathrm{m}^{2}\right)$

Time interval (Seconds)

Outlet temperature from evacuated tube collector

Specific heat capacity of water $(\mathrm{J} / \mathrm{kgK})$

Mass of the vessel $(\mathrm{kg})$

Convective heat coefficient from vessel base surroundings (W/mK)

Cooking base vessel temperature $(\mathrm{K})$

Vessel base near temperature $(\mathrm{K})$

Cooking side vessel temperature (K) 
$401 \quad T_{c f} \quad-\quad$ Temperature with cooking fluid (K)

$402 \quad m \quad-\quad$ Cooking fluid mass $(\mathrm{kg})$

$403 \quad C_{f} \quad-\quad$ Cooking fluid with specific heat capacity $(\mathrm{J} / \mathrm{kgK})$

404

$405 \quad$ Funding Statement

406 The authors would say thanks a lot to Department of Science and Technology (DST,

407 Delhi), Government of India for the award of DST-FIRST Level-1(SR/FST/PS-1/2018/35) scheme

408 to the Department of Physics. Appreciations are grateful to the KLEF offering infrastructure,

409 facilities, basic found (Perform basic instruments) and support to the current investigation.

411 Conflict of Interest

412 There is no conflict of interest among the authors.

413

414 Author Contributions

415 Mr. Arulraj Simon Prabu

416 Synthesis of Experimental work design and characterization of Solar cooker

417 Dr Venkatesan Chithambaram

418 Analysis of results

419 Dr Maria Anto Bennet

420 Data validation, Editing of the manuscript

421 Dr. Sengottaiyan Shanmugan

422 Analysis of results, writing the manuscript, reviewing and editing the paper

423 Dr. Catalin Iulian Pruncu

424 An editing the paper

425 Dr. Luciano Lamberti

426 Data validation, Editing of the manuscript

427 Dr. Ammar Hamed Elsheikh

428 Data validation, Editing of the manuscript

429 Dr. Hitesh Panchal

430 Data validation, Editing of the manuscript 


\section{Dr. Balasubrimani Janarthanan}

433 Data validation, Editing of the manuscript

\section{Availability of Data and Material}

436 The designed solar cooker and data of results of characterization are available.

\section{Compliance with ethical standard}

439 The research work is ethically complied.

\section{Consent to participate}

442 All the authors give their consent to having participated in the current work.

\section{Consent for publication}

445 All the authors give their consent for publication of this work.

\section{References}

448 Arman Nokhosteen and Sarvenaz Sobhansarbandi (2020) Novel method of thermal behavior 449 prediction of evacuated tube solar collector. Solar Energy, 204: 761-768 DOI: 10.1016/j.solener.2020.05.008

452 Ashmore Mawire, Katlego Lentswe, Prince Owusu, Adedamola Shobo, Jo Darkwa, John Calautit 453 and Mark Worall (2020) Performance comparison of two solar cooking storage pots combined 454 with wonder bag slow cookers for off-sunshine cooking. Solar Energy 208: 1166-1180 455 https://doi.org/10.1016/j.solener.2020.08.053

457 Atul Bhave and Chirag Kale (2020) Development of a thermal storage type solar cooker for high 458 temperature cooking using solar salt. Solar Energy Materials and Solar Cells 208: 110394 DOI: $459 \quad 10.1016 /$ j.solmat.2020.110394

461 Arunachala UC and Ashok Kundapur (2020) Cost-effective solar cookers - A review. Solar 462 Energy 207: 903-916 https://doi.org/10.1016/j.solener.2020.07.026 
Bhavani S, Shanmugan S, Chithambaram V, Essa FA, Kabeel AE, Selvaraju P (2021) Simulation

465 study on thermal performance of a Solar box Cooker using nanocomposite for natural Food 466 invention. Environmental Science and Pollution Research https://doi.org/10.1007/s11356-021467 14194-W

Bhavania S, Shanmugan S, Selvaraju P, Monisha C, Suganya V (2019) Fuzzy Interference Treatment applied to Energy Control with effect of Box type Affordable Solar Cooker. Materials Today: Proceedings 18(3): 1280-1290 https://doi.org/10.1016/j.matpr.2019.06.590

Bhavani S, Shanmugan S, Selvaraju P (2018) High Performance of Solar Cooker by Heat Transfer

474 Mode Condition System Using Fuzzy Logic Controller Applications. International Journal of 475 Engineering \& Technology 7(4.10): 278-281 DOI: 10.14419/ijet. v7i4.10.20912

Devan PK, Chidambaranathan, Bibin, Gowtham S, Hariharan G, Hariharan R (2020) A comprehensive review on solar cooker with sun tracking system, Materials Today: Proceedings 33(1): 771-777 https://doi.org/10.1016/j.matpr.2020.06.124

Gianluca Coccia, Alessia Aquilanti, Sebastiano Tomassetti, Gabriele Comodi and Giovanni Di Nicola (2020) Design, realization, and tests of a portable solar box cooker coupled with an erythritol-based PCM thermal energy storage. Solar Energy 201: 530-540 https://doi.org/10.1016/j.solener.2020.03.031

Mohammad Hosseinzadeh, Reza Sadeghirad, Hosein Zamani, Ali Kianifar, Seyyed Mahdi Mirzababaee and AliFaezian (2021) Experimental study of a nanofluid-based indirect solar cooker: Energy and exergy analyses. Solar Energy Materials and Solar Cells, Vol. 221, pp. 110879 https://doi.org/10.1016/j.solmat.2020.110879

491 Mohammad Hosseinzadeh, Reza Sadeghirad, Hosein Zamani, Ali Kianifar, Seyyed Mahdi 492 Mirzababaee and AliFaezian (2021) The performance improvement of an indirect solar cooker 493 using multi-walled carbon nanotube-oil nanofluid: An experimental study with thermodynamic 494 analysis. Renewable Energy 165(1): 14-24 https://doi.org/10.1016/j.renene.2020.10.078 
496 Masum Ahmed SM, Rahmatullah Al-Amin MD, Shakil Ahammed, Foysal Ahmed, Ahmed 497 Mortuza Saleque. Abdur Rahman MD (2020) Design, construction and testing of parabolic solar 498 cooker for rural households and refugee camp. Solar Energy 205: 230-240 499 https://doi.org/10.1016/j.solener.2020.05.007

Mohammad Hosseinzadeh, AliFaezian, Seyyed Mahdi Mirzababaee, Hosein Zamani (2020)

502 Parametric analysis and optimization of a portable evacuated tube solar cooker. Solar Energy 194: 116816 https://doi.org/10.1016/j.energy.2019.116816

Omara AAM, Abuelnuor AA, Mohammed HA, Daryoush Habibi, Obai Younis (2020) Improving solar cooker performance using phase change materials: A comprehensive review. Solar Energy 207: 539-563 https://doi.org/10.1016/j.solener.2020.07.015

Palanikumar G, Shanmugan S, Chithambaram V (2021) Solar cooking thermal image processing applied to time series analysis of fuzzy stage and inconsiderable Fourier transform method. Materials Today: Proceedings 34(2): 460-468 https://doi.org/10.1016/j.matpr.2020.02.664

513 Palanikumar G, Shanmugan S, Chithambaram V, Selvaraju P (2019) Evaluation of fuzzy inference

514 in box type solar cooking food image of thermal effect. Environmental and Sustainability 515 Indicators 1-2: 100002 https://doi.org/10.1016/j.indic.2019.100002

517 Rakesh Kumar, Adhikari RS, Garg HP Ashvini Kumar (2001) Thermal performance of a solar 518 pressure cooker based on evacuated tube solar collector. Applied Thermal Engineering 21(16): 1699-1706 https://doi.org/10.1016/S1359-4311(01)00018-7

521 Shanmugan S, Shiva Gorjian, Ammar Hamed Elsheikh, Essa FA, Zakaria Mohamed Omara,

522 Venkataramanaiah Raghu A. (2020) Investigation into the effects of $\mathrm{SiO}_{2} / \mathrm{TiO}_{2}$ nanolayer on the 523 thermal performance of solar box type cooker. Energy Sources Part A: Recovery Utilization and 524 Environmental Effects https://doi.org/10.1080/15567036.2020.1859018 
526 Sharma SD, Takeshi Iwata, Hiroaki Kitano, Kazu Nobu Sagara (2001) Thermal performance of 527 a solar cooker based on an evacuated tube solar collector with a PCM storage unit. Solar Energy 528 78(3): 416-426 https://doi.org/10.1016/j.solener.2004.08.001

530 Thamizharasu P, Shanmugan S, Gorjian S, Pruncu CI, Essa F A, Panchal H, Harish M (2020) 531 Improvement of Thermal Performance of a Solar Box Type Cooker Using $\mathrm{SiO}_{2} / \mathrm{TiO}_{2}$ Nanolayer. 532 Silicon 1-9 https://doi.org/10.1007/s12633-020-00835-1

534 Thamizharasu P, Shanmugan S, Sivakumar S, Pruncu CI, Kabeel AE, Nagaraj J, Lakshmi Sarvani 535 Videla, Vijai Anand K, Lamberti L, Meena Laad (2021) Revealing an OSELM based on traversal 536 tree for higher energy adaptive control using an efficient solar box cooker. Solar Energy 218: 320537336 https://doi.org/10.1016/j.solener.2021.02.043

538

539 Thirugnanam C, Karthikeyan S, Kalaimurugan K (2020) Study of phase change materials and its 540 application in solar cooker. Materials Today: Proceedings 33(1): 2890-2896 541 https://doi.org/10.1016/j.matpr.2017.11.586 


\section{Figures}
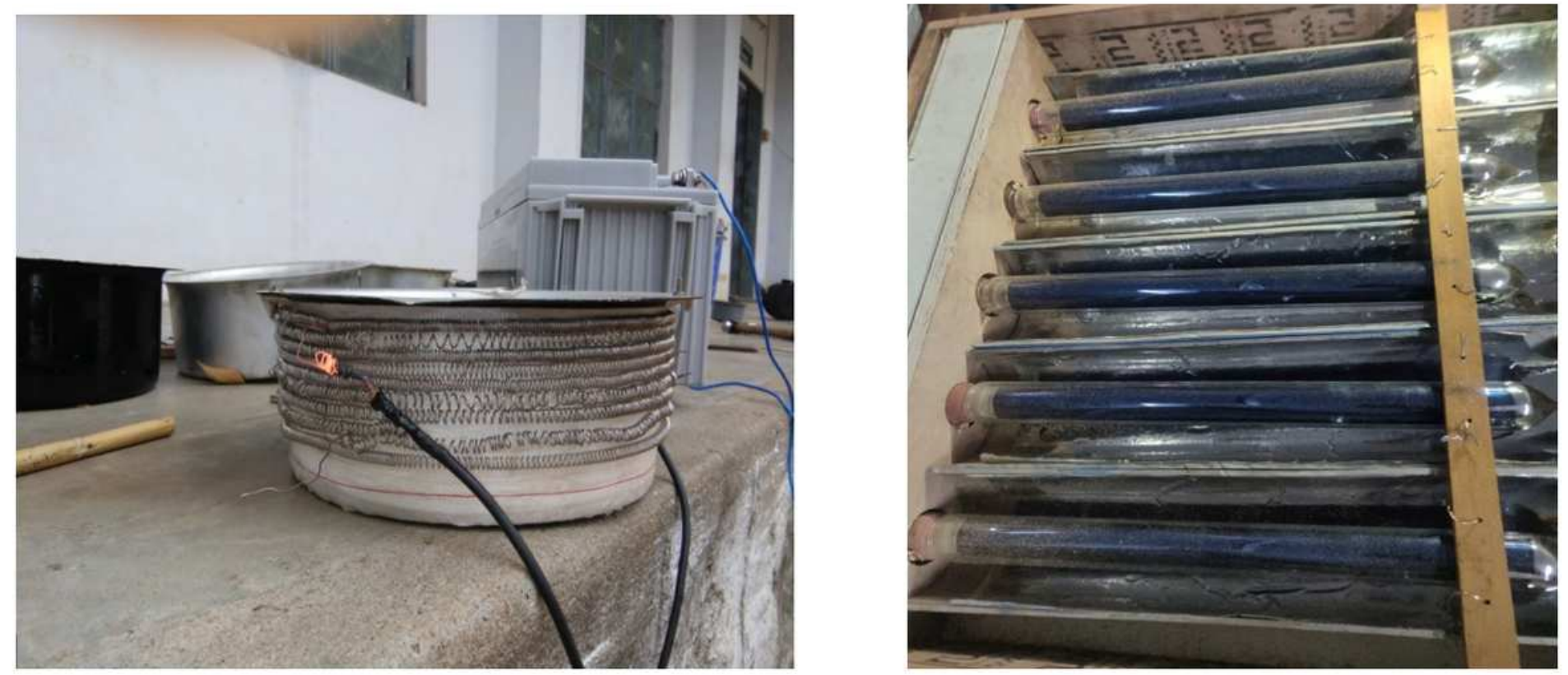

Figure 1

Photograph of Cooking vessel with Nichrome heating coil and evacuated tube collector.
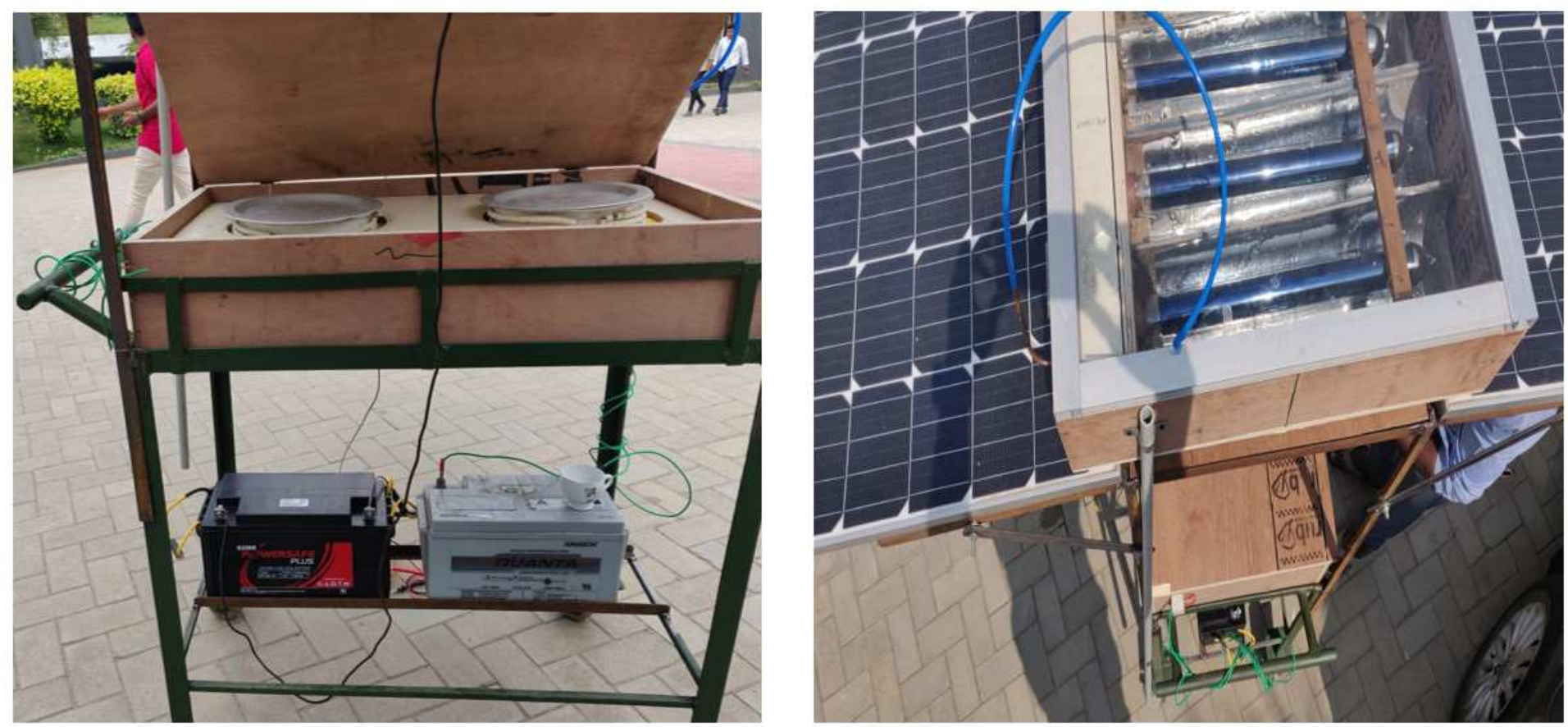

Figure 2

Photograph of the solar panel with battery and charge controller. 

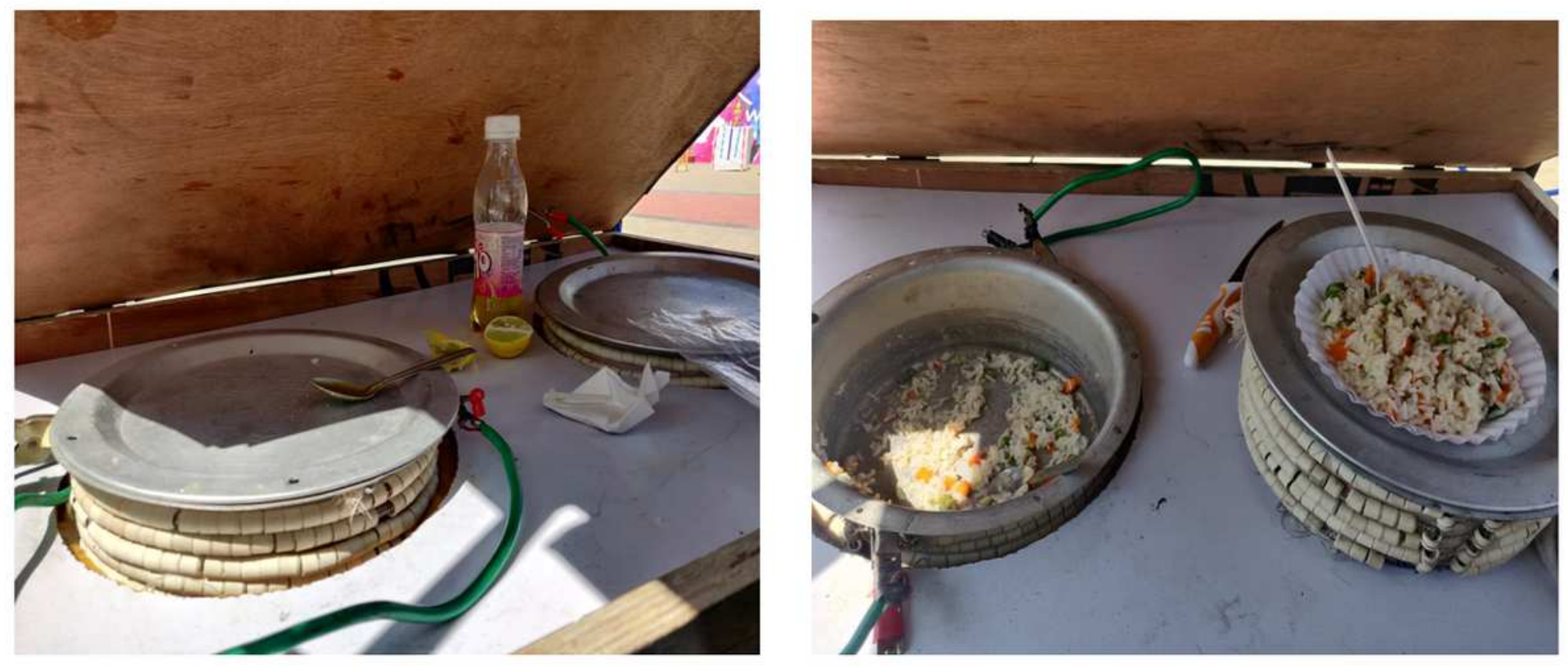

Figure 3

Photograph of the food cooked using solar cooker.

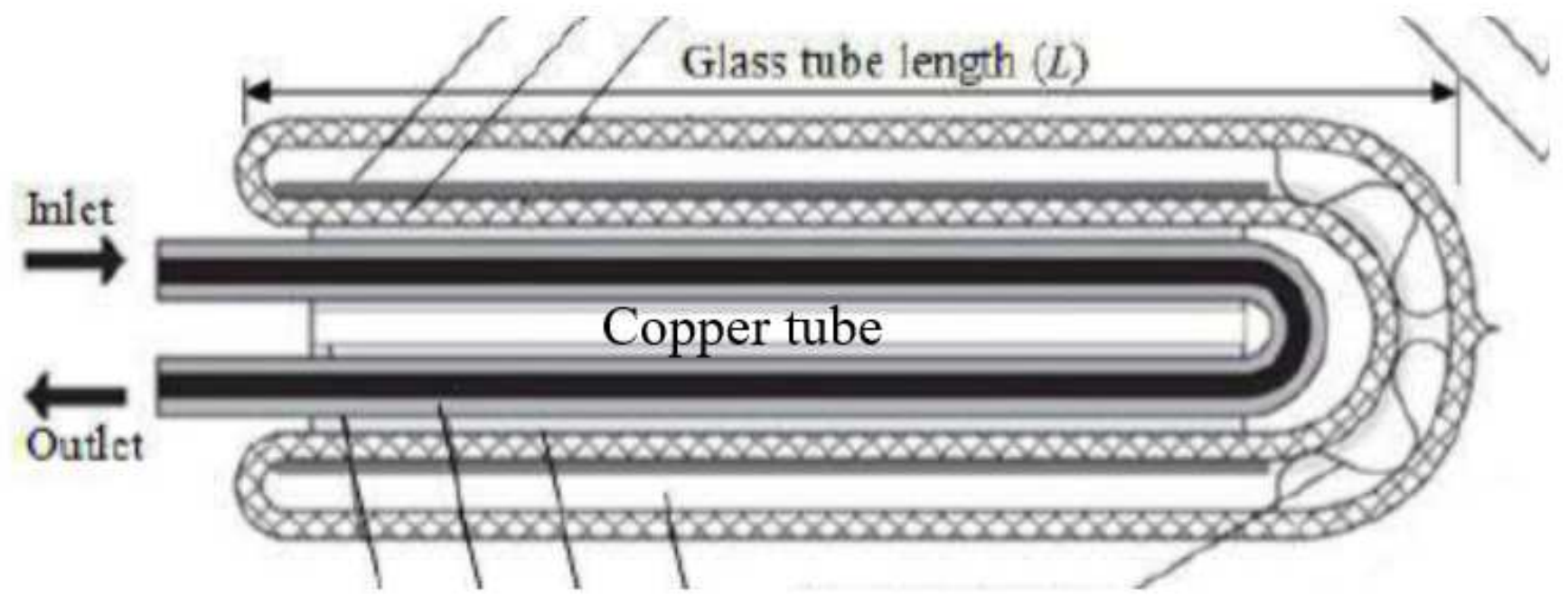

Figure 4

Schematic diagram of the evacuated tube into which is inserted the u-type copper tube. 


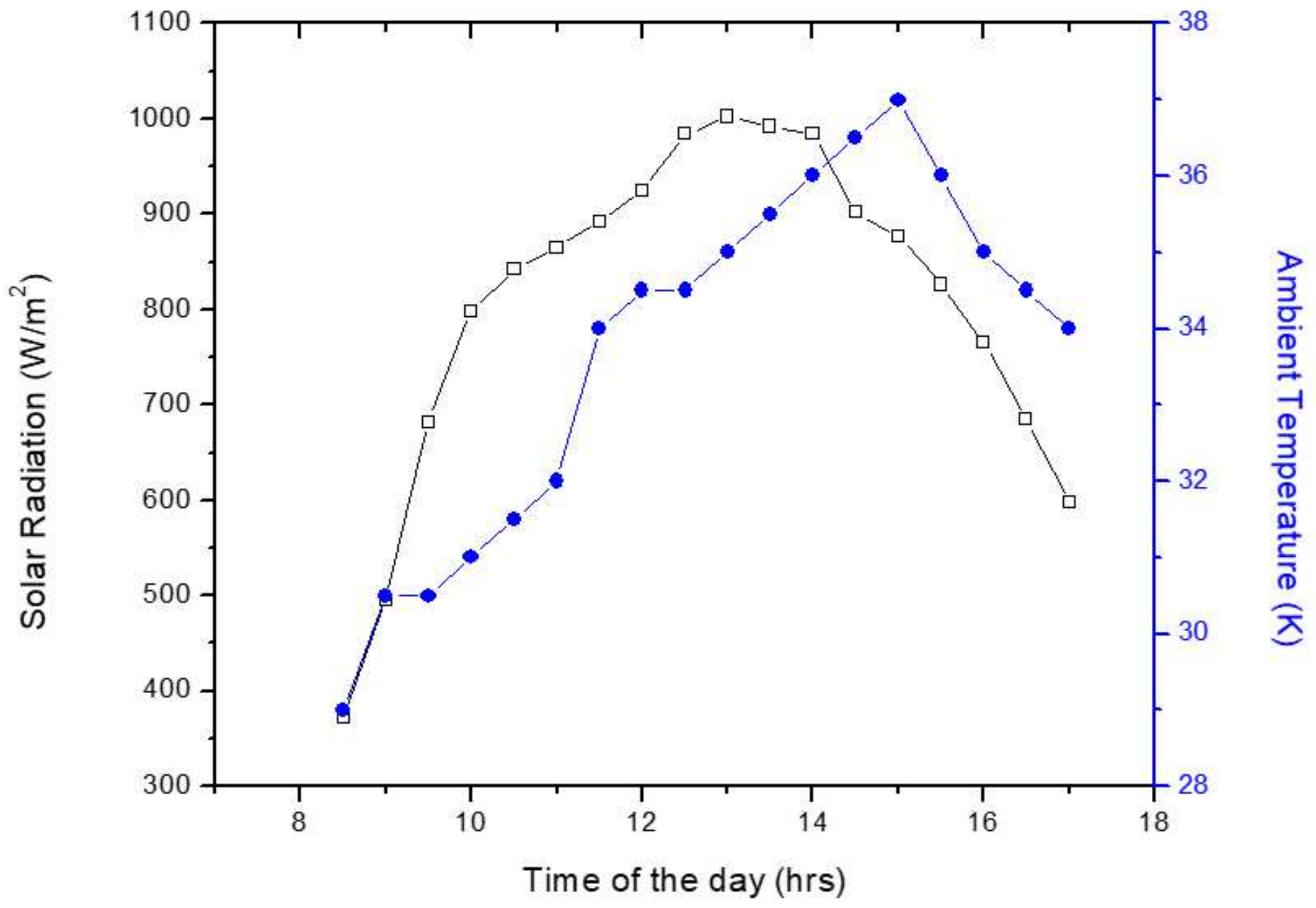

Figure 5

Solar radiation \& ambient temperature recorded over a typical working day. 


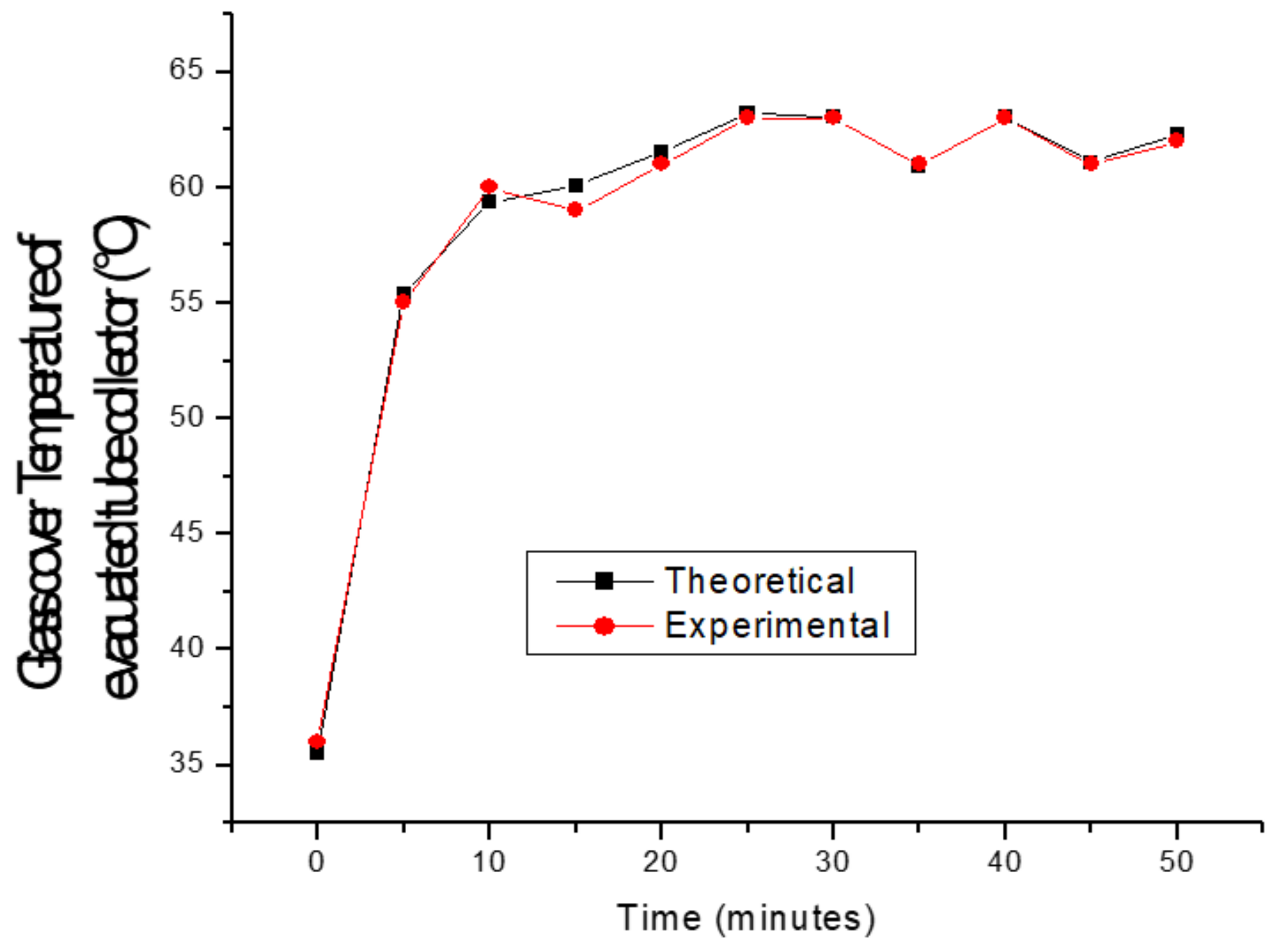

Figure 6

Variation of temperature of glass cover of evacuated tube collector with respect to time. 


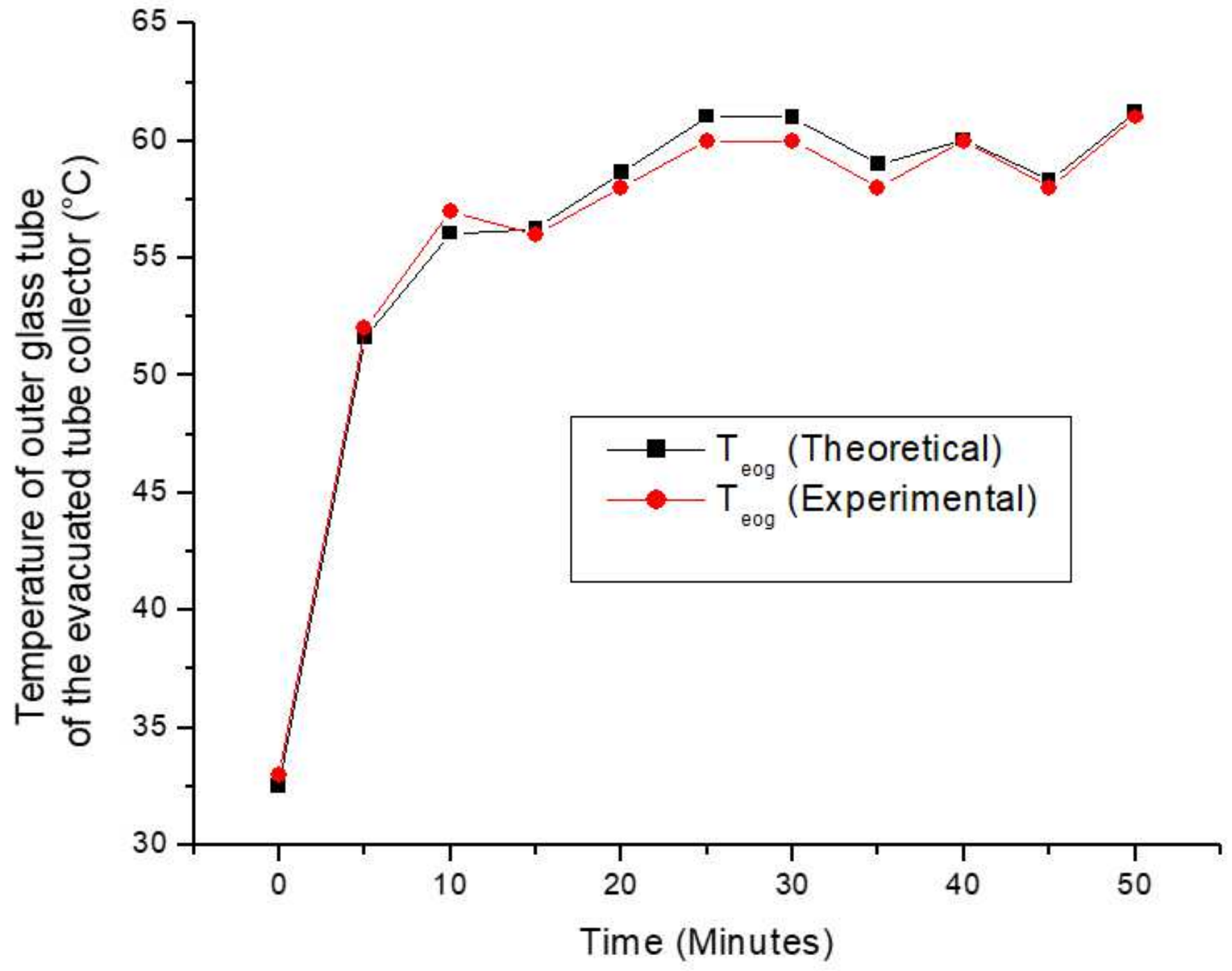

Figure 7

Experimental and theoretical temperature variations for the outer glass tube of the evacuated tube collector. 


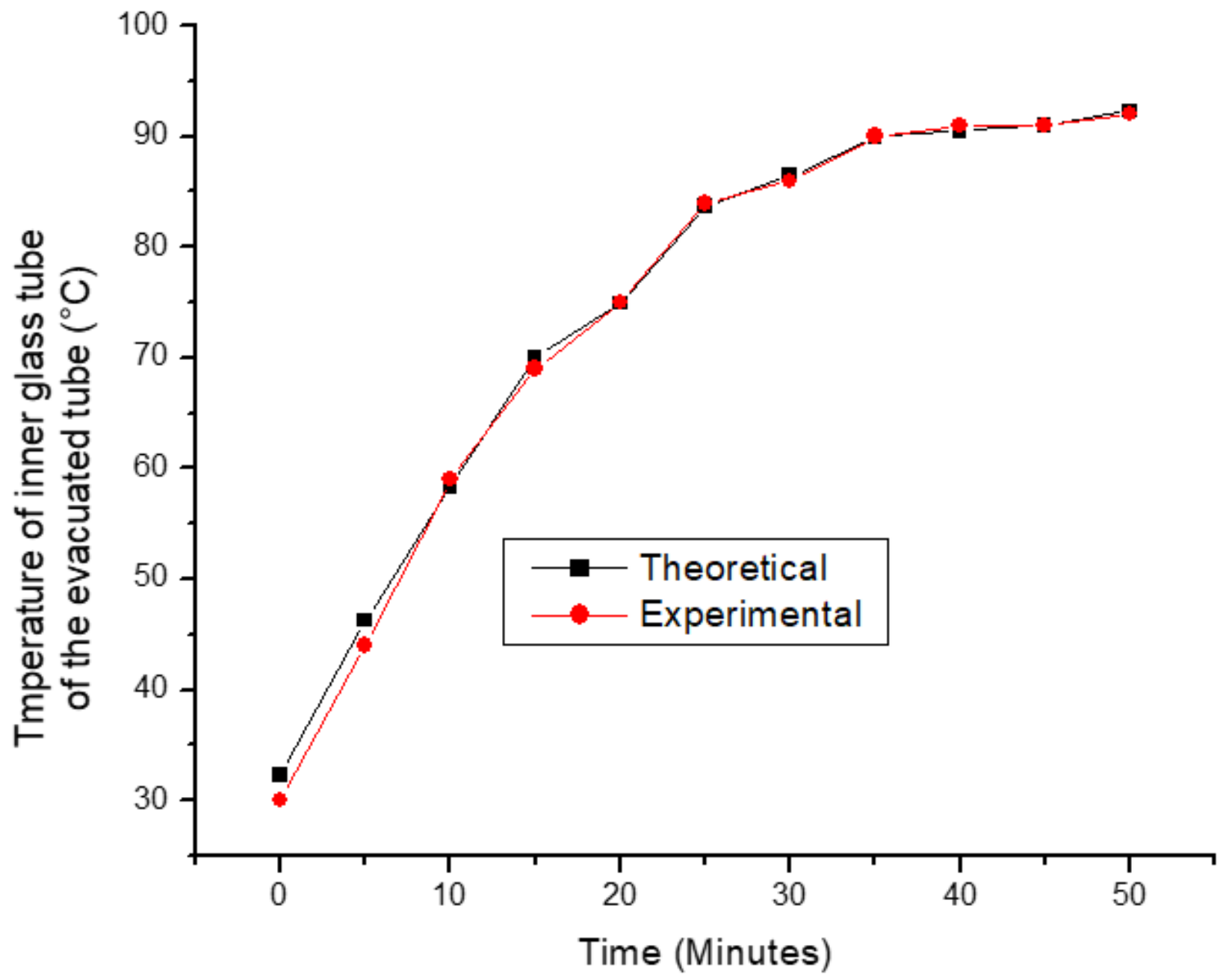

Figure 8

Temperature variations (experimental and theoretical) of the inner glass tube of the evacuated tube with respect to time. 


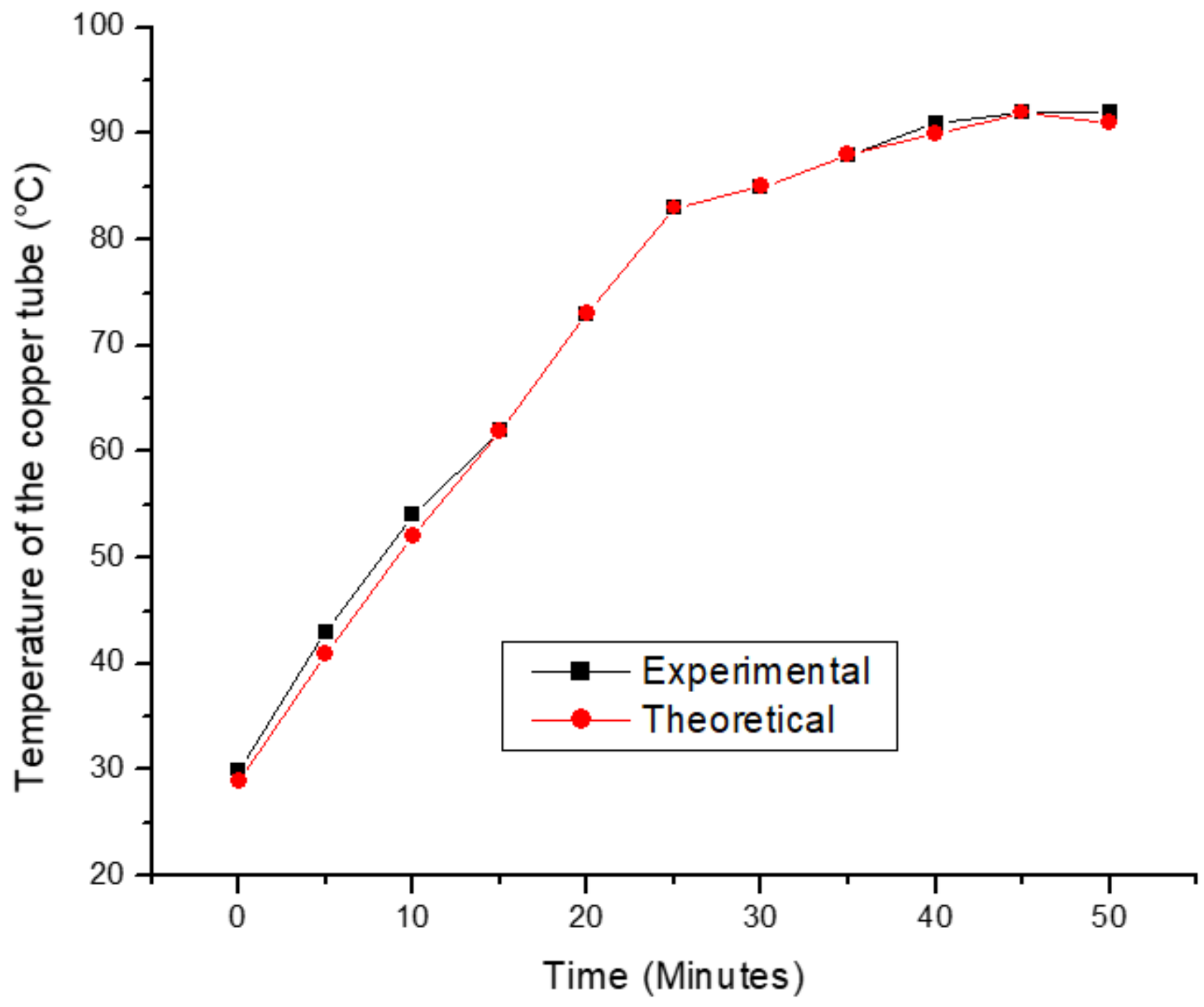

Figure 9

Experimental and theoretical temperature values for the copper tube with respect to time. 


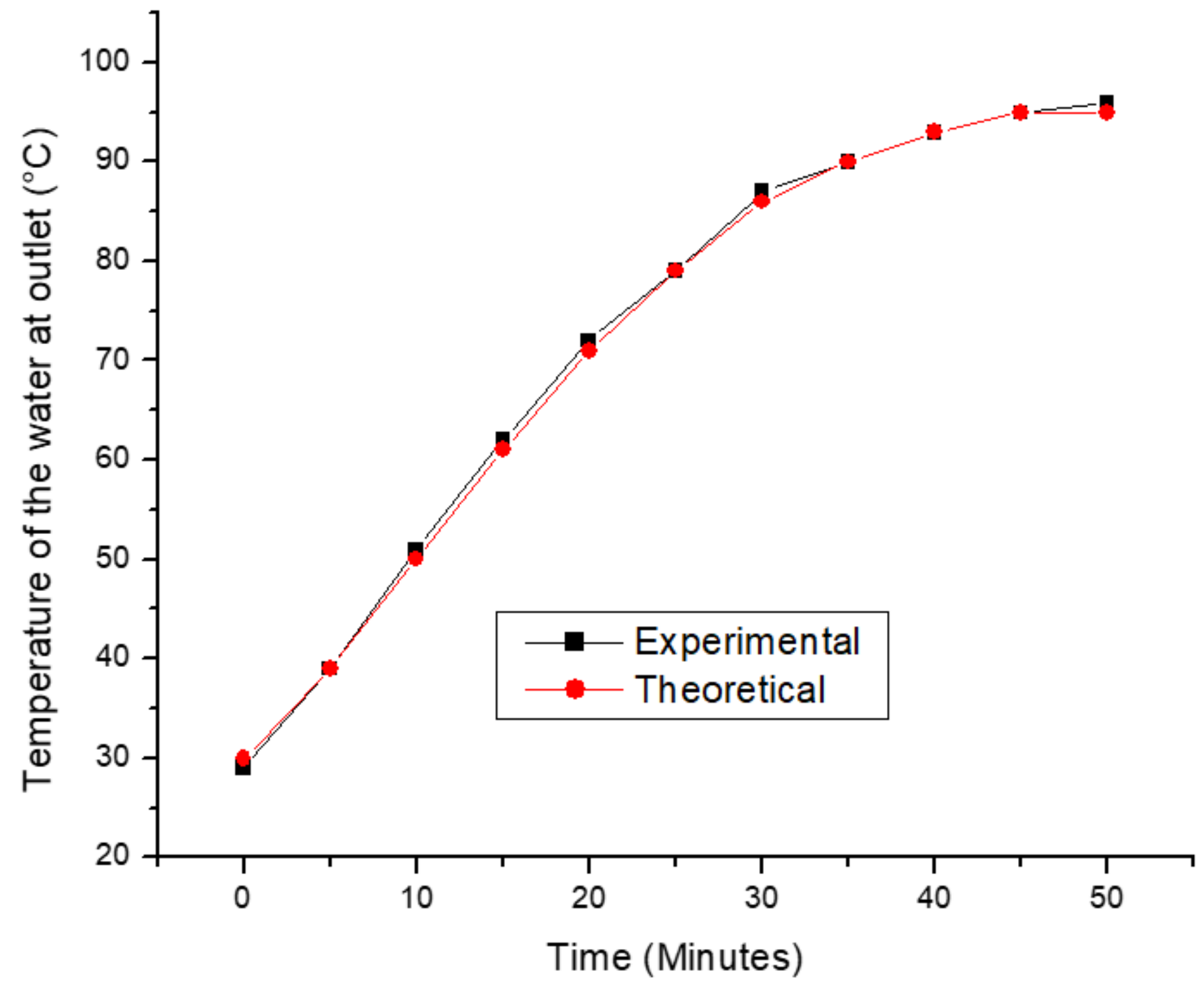

Figure 10

Temperature variations (experimental and theoretical) of water at the outlet of the evacuated tube collector. 


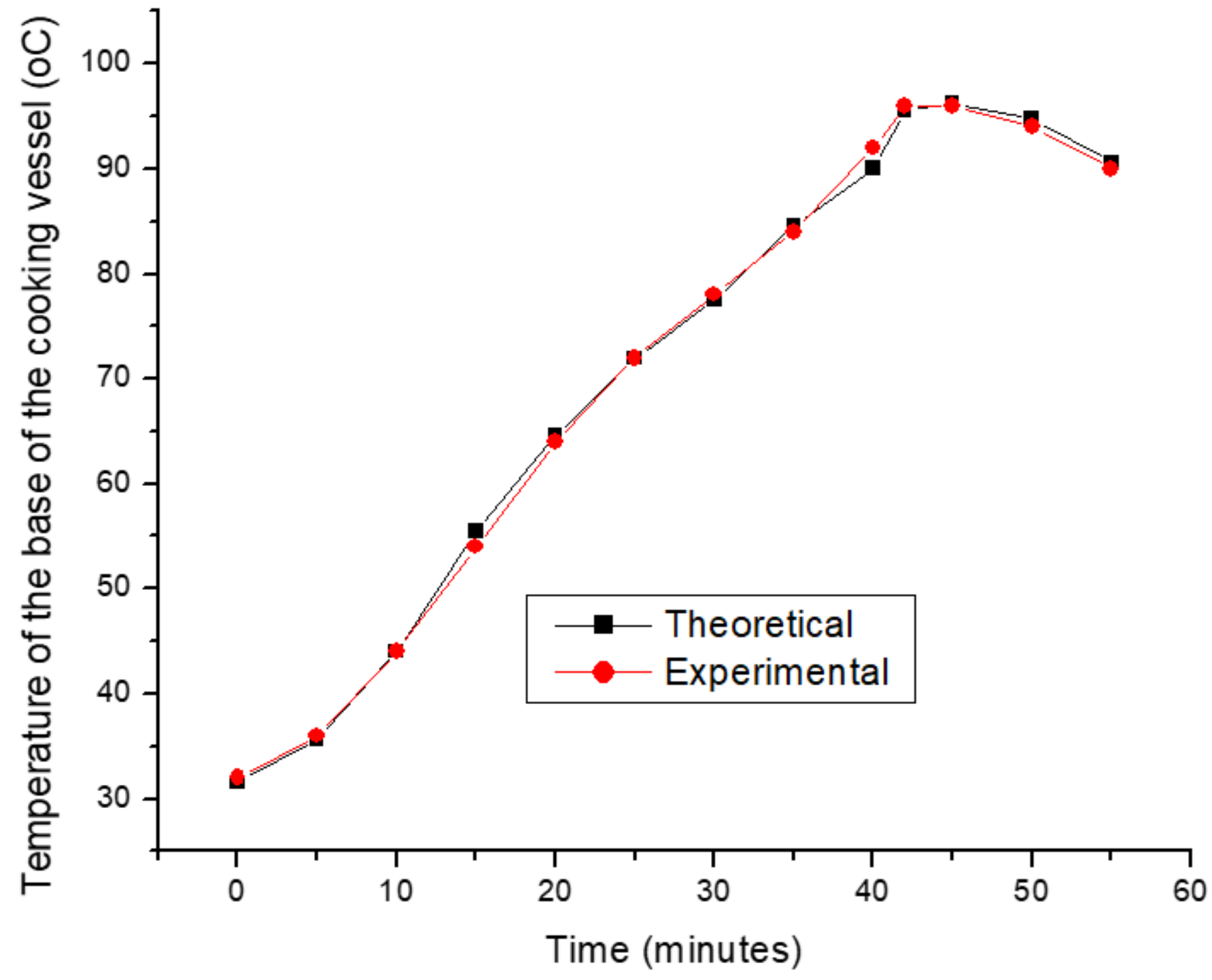

Figure 11

Variation of the temperature of cooking vessel base vs. time. 


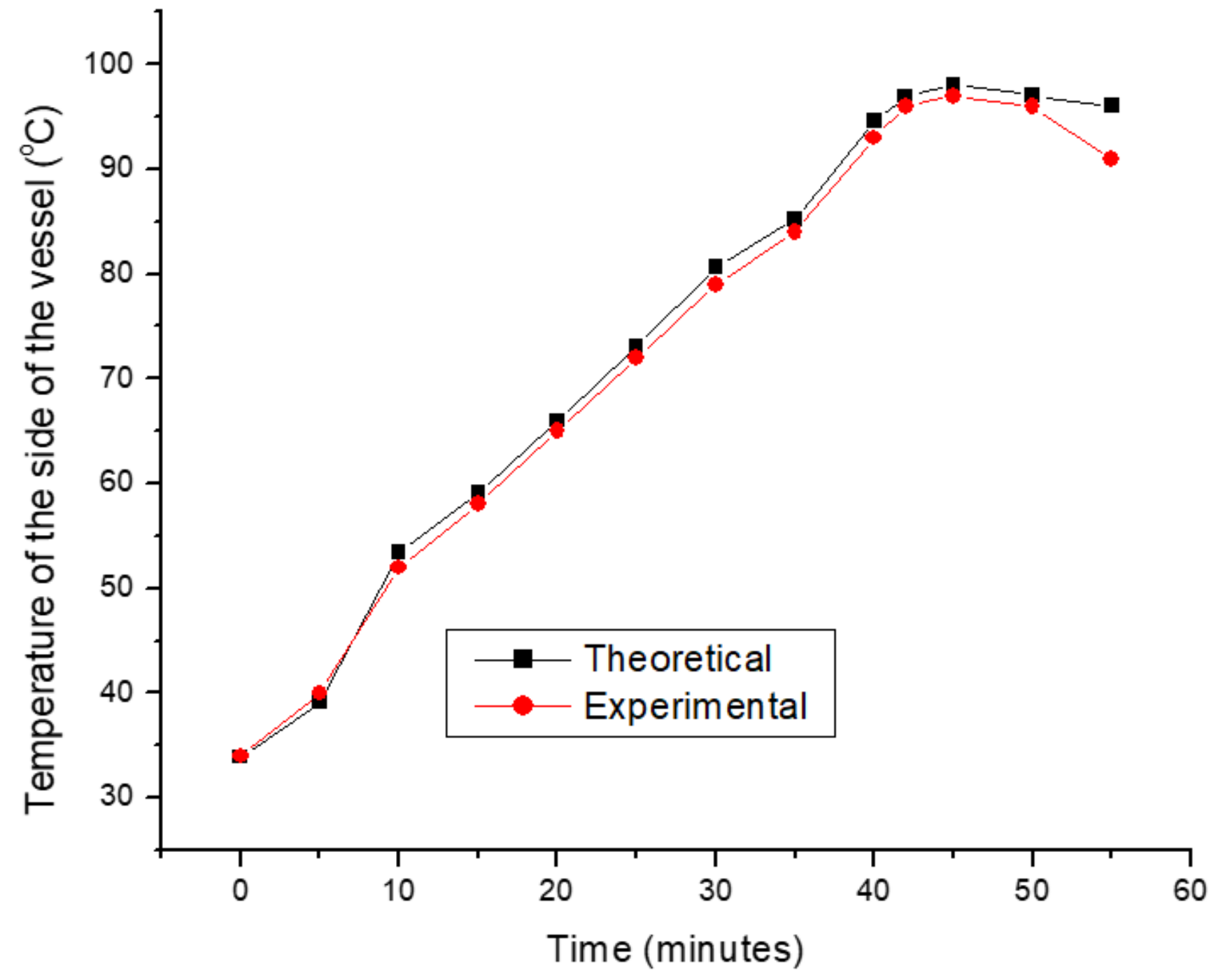

Figure 12

Variation of the temperature of cooking vessel sides vs. time. 


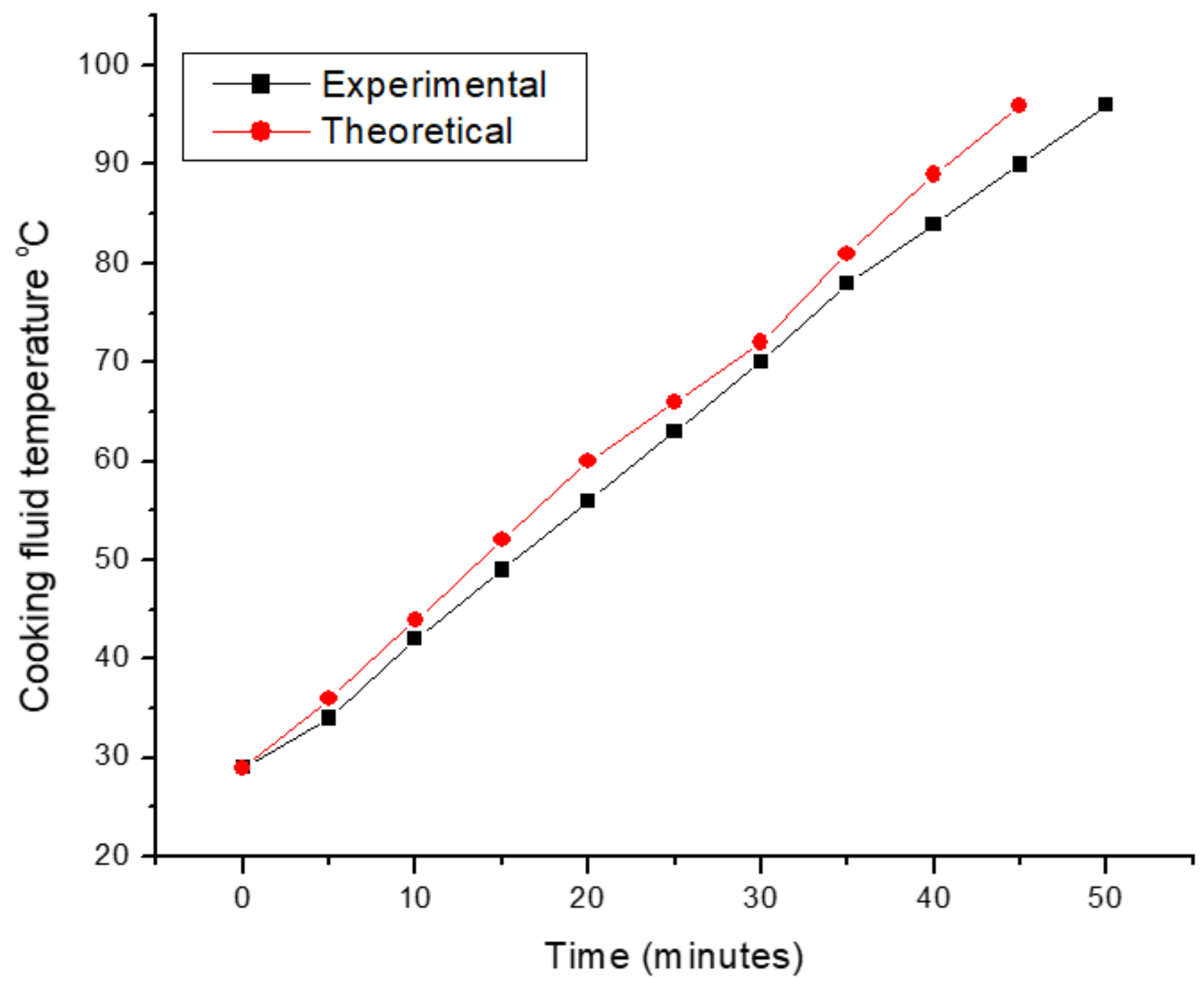

Figure 13

Experimental and theoretical values of temperature of the cooking fluid. 